\title{
Influence of Roasting on Sensory, Antioxidant, Aromas, and Physicochemical Properties of Carob Pod Powder (Ceratonia siliqua L.)
}

\author{
Ikram Boublenza, ${ }^{1}$ Hamadi Abderrahmane Lazouni, ${ }^{1}$ Leila Ghaffari, ${ }^{2}$ Karine Ruiz, ${ }^{2}$ \\ Anne-Sylvie Fabiano-Tixier, ${ }^{2}$ and Farid Chemat ${ }^{2}$ \\ ${ }^{1}$ Laboratoire Produits Naturels (LAPRONA), Université de Tlemcen, 13000 Tlemcen, Algeria \\ ${ }^{2}$ INRA, UMR408, GREEN Extraction Team, Université d'Avignon, 84000 Avignon, France \\ Correspondence should be addressed to Ikram Boublenza; iboublenza@hotmail.fr \\ and Farid Chemat; farid.chemat@univ-avignon.fr
}

Received 8 June 2017; Revised 28 July 2017; Accepted 17 August 2017; Published 11 October 2017

Academic Editor: Daming Fan

Copyright ( 2017 Ikram Boublenza et al. This is an open access article distributed under the Creative Commons Attribution License, which permits unrestricted use, distribution, and reproduction in any medium, provided the original work is properly cited.

\begin{abstract}
The main objective of this research was to compare physicochemical parameters, antioxidant activity, lipid composition, and sensory analysis of initial and roasted carob pod powder (Ceratonia siliqua L.) obtained at different roasting temperatures. The roasted products became darker and the average moisture content, water activity, oil content, and sweetness values decreased at higher temperatures. Total polyphenol content and antioxidant activity increased with increasing roasted temperature. Oleic acid, linoleic acid, and palmitic acid were the main fatty acids present in carob oil. Results showed that the roasted carob pod powders are sweeter, have more caramel-like taste, and have more cacao-like aroma at lower roasting temperatures but have more astringent taste, coffee-like aroma, and roasted aroma at higher roasting temperatures.
\end{abstract}

\section{Introduction}

Ceratonia siliqua L. (carob) is an evergreen tree belonging to the Caesalpinioideae subfamily of Leguminosae family [1-6]. The scientific name of carob tree derives from Greek keras, horn and Latin siliqua, indicating the hardness and shape of the pod. It is also known as St. John's bread with reference to its presumed use by St. John the Baptist [7]. The centre of origin of C. siliqua carob pod powder was recognized in the eastern Mediterranean region (Turkey and Syria). The Greeks introduced carob in some European countries, like Greece and Italy, and the Arabs spread it along the North African coast and north into Spain and Portugal [8].

Carob was spread in recent times to other Mediterraneanlike regions such as California, Arizona, Mexico, Chile, and Argentina by Spaniards, to parts of Australia by Mediterranean emigrants and to South Africa and India $[9,10]$. Carob has been used for over 4000 years as feed and food, especially in times of food shortage, mainly due to its sugary pulp [11-13]. Carob kibbles are traditionally used to make a boiled juice product, named "pekmez," which is mainly consumed in Turkey [14-17]. About 8 percent of the high cholesterol sufferers know and use carob in Turkey. They usually mash the carob kibbles and eat it either with yogurt or raw, in order to lower their cholesterol [18]. In the Middle East, carob is usually well known among people as purgative, antidiarrheal, and antiulcer. It is also used to treat mouth inflammation and tonic in this area (Jaradat) [19]. Lev and Amar [20] reported that, in Kingdom of Jordan, the carob kibble is known as stomach strengthener and phlegm clearer; the carob jam is also used for tongue sores and stomachache treatments and the seed is usually used as purgative and toothache calmative. Some researchers have also reported carob uses for its therapeutic virtues as diuretic, antidiarrheal, antitussive, and warts remover [21-23]. Today, the world carob fruit production is estimated at 315000 tons per year [24]. In Algeria, the most carob trees are wild and grow in north and northwest of the country. The annual production of 
carob attains 3000 tons per year [10]. Local farmers manually do the harvesting of the whole fruits at the end of the summer from August to October.

Ripe carob pod is brown and contains 10-20\% of carob kernels or seeds and $80-90 \%$ of carob kibbles $[4,9,25,26]$. The seeds, surrounded by a brown coat, contain a white and translucent endosperm (also called carob gum, locust bean gum (LBG), or E410) and the yellow germ which is recovered as the byproduct of the seed processing [26, 27]. Locust bean gum is widely used in the food industry as thickening and stabilizing agent in food preparations because of its ability to form viscous solution at relatively low concentration. It is also used in the cosmetic, pharmaceutical, textile, paper, petroleum, paint, oil drilling, and construction industries $[10,13,27,28]$. Carob germ flour is used as dietetic human food or as a potential ingredient in cereal-derived foods for celiac people [29]. Carob kibbles can be used raw, usually for animal feeding, or roasted, in food industry [10, 11, 14]. They are also used to extract sugars for making syrup or bioethanol $[17,30-32]$. The biological activities of the fruit of carob tree are mainly related to the inositol and the polyphenols present in the kibble, galactomannan in the endosperm, and protein content in the germ of kernel of this fruit $[10,26,27,33]$.

In recent years, carob pulp which is a byproduct is becoming more popular for its organoleptic properties, aroma, color, and taste, and also for its dietary quality. Having a cocoalike aroma of roasted carob, carob pulp is mainly roasted and grinded to powder to be used as cocoa substitute. Unlike cocoa powder, carob is free from the two stimulants caffeine and theobromine $[14,34]$. Besides this, carob contains a high amount of sugar, mostly sucrose, and it is also rich in dietary fibers and poor in protein and fat; therefore it has less energy value than cocoa $[24,35]$. Carob powder contains daily nutritional amount of potassium, calcium, magnesium, and iron $[15,36]$. It is reported that carob comprises a high amount of pinitol, which has beneficial effects on human health, such as the regulation of blood glucose levels and reduction of hyperlipidemia and inflammation [37, 38]. Containing a large amount of bioactive compounds, carob kibble has shown good antioxidant activities [2, 10, 39, 40], anticancer and antiproliferation effects [41], antidiabetic effect [42, 43], cholesterol lowering effect $[44,45]$, and antimicrobial effects [23] and it has positive effects on cardiovascular diseases $[42,46]$.

The objective of this work is valorization of carob pulp, which is a byproduct of processing carob to get seeds for carob gum, into roasted carob powders which could be used directly or as a raw material for producing aromas. This global study aims to compare physicochemical parameters, antioxidant activity, lipid composition, sensory analysis of initial and roasted carob powders obtained at different roasted temperatures. This study will permit investigating the possible synergistic effects of the mentioned parameters on final roasted carob powder.

\section{Materials and Methods}

2.1. Sample. Ripe carob pods were harvested from Tlemcen region, west Algeria. The fruits were cleaned, mixed, and crushed and the seeds were removed. Then, the carob kibbles were roasted at different time/temperature conditions in an artisanal roaster (Figure 1). Grinding roasted carob in grinder was followed by sieving powders at granulation less than $100 \mu$, which was the ultimate operation for preparing samples to be analyzed. The initial grinded carob pulp, C0, was just dried at $110^{\circ} \mathrm{C}$. The roasted carobs $\mathrm{C} 1, \mathrm{C} 2$, and $\mathrm{C} 3$ have been roasted consecutively at temperatures $110^{\circ} \mathrm{C}, 130^{\circ} \mathrm{C}$, and $150^{\circ} \mathrm{C}$.

2.2. Moisture Analysis. To determine the moisture, an aluminum cup was filled with about $1 \mathrm{~g}$ of extract and placed in an infrared balance (Sartorius MA 150, France), which is based on the thermogravimetric principle. In the beginning, the initial weight of the sample was recorded and afterwards, the sample was dried using an infrared lamp. An integrated balance measured the weight of the aluminum cup, continuously. The overall weight loss was interpreted as the corresponding humidity.

2.3. Water Activity Analysis. The aw value was measured using the VSA (Vapor Sorption Analyser, AQUALAB, France). $300 \mathrm{mg}$ of powder was placed in an inox cup, which was then introduced into the device, and the aw was determined by using a chilled-mirror dew point sensor. The dew point is defined as the temperature at which the air is saturated with water and begins to form droplets. The mirror was cooled until the dew was formed, which was detected by a photodetector. A temperature sensor was used to determine the dew point, with which the device was then able to deduce the water activity of the sample.

2.4. $\mathrm{pH}$ Evaluation. After calibration of the $\mathrm{pH}$ meter Hanna $\mathrm{HI} 2002$, the $\mathrm{pH}$ samples of different powders were measured in triplicate. The concentration of each solution was at $10 \% \mathrm{~m} / \mathrm{v}$.

2.5. Color Assessment. The color of the products was measured using the Chromameter Konica Minolta CR-410 $L^{*} a^{*} b^{*}$ system, which is a simplified mathematical approximation to a uniform color space, composed of perceived color differences. Any color represented in the rectangular coordinate system of axes $L^{*}, a^{*}$, and $b^{*}$ can alternatively be expressed in terms of polar coordinates with the perceived lightness $L^{*}$ and the psychometric correlate of chroma $\left(C^{*}\right)$ as shown in the equation $[47,48]: C^{*}=\left(a^{* 2}+b^{* 2}\right)^{1 / 2}$. Three measurements were made for each powder preparation and the mean value was reported. The results were expressed in $C^{*}$. Detailed analysis has been explained and detailed in our previous publication (Pingret et al. 2011) [47].

2.6. Total Sugars Analysis and Sucrose, Glucose, and Fructose Analysis. The phenol-sulphuric acid method known by Dubois method was used to evaluate total sugars of unroasted carob and different roasted powders. Five grams of each powder was mixed with $50 \mathrm{~mL}$ of water with Ultra-Turrax and then passed to centrifugation. The supernatant was transferred into tubes by PIPETMAN to avoid any floating particles and diluted at 1/500 to obtain the adequate values 


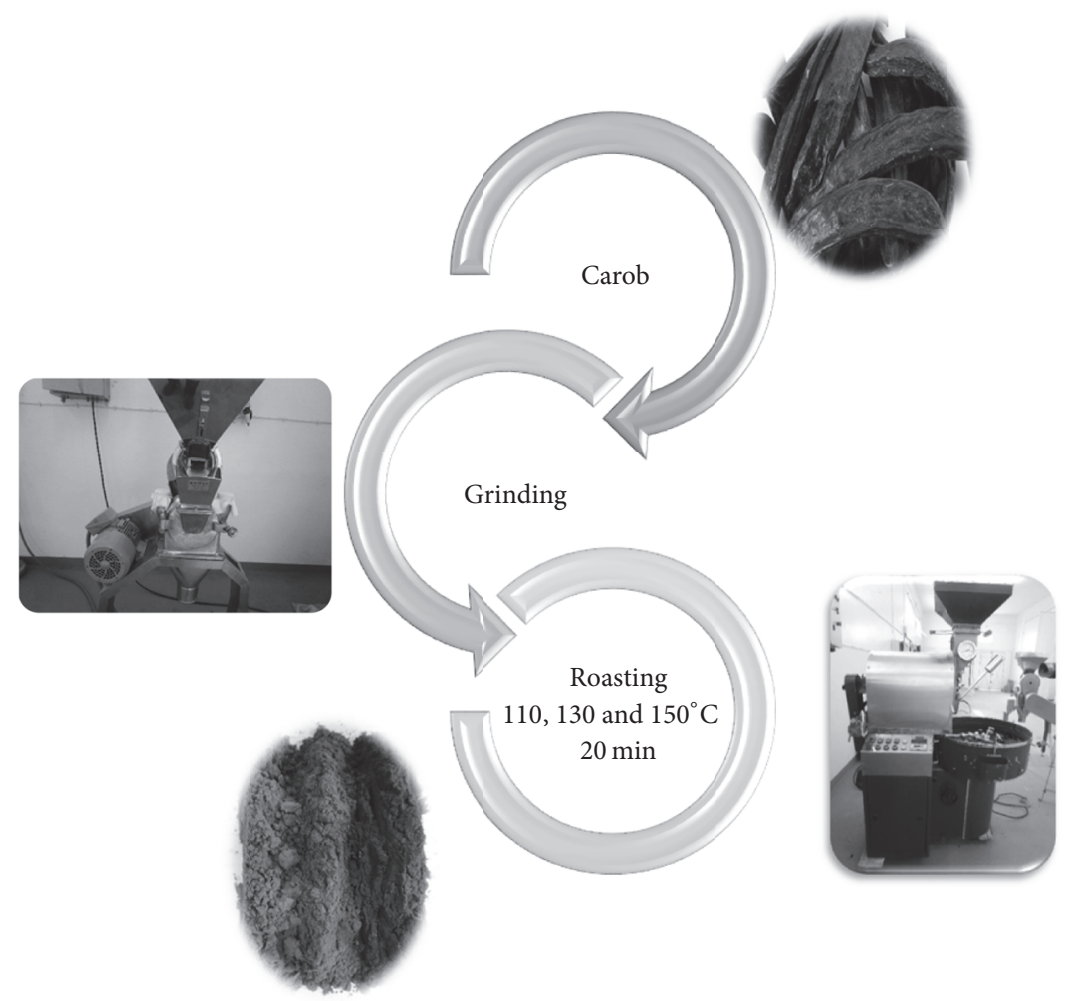

FIGURE 1: Roasting process of carob pulp.

comparing to the standards of glucose values. $2 \mathrm{~mL}$ of diluted solution was put in tube containing $1 \mathrm{~mL}$ of phenol $5 \%$ and then, $5 \mathrm{~mL}$ of concentrate sulphuric acid was added and left in water bath at $25-30^{\circ} \mathrm{C}$ for $20 \mathrm{~min}$. These tubes were immediately cooled at $20^{\circ} \mathrm{C}$ with tap water. The absorbance was measured at $485 \mathrm{~nm}$ with spectrophotometer Jenway 700 against the blanks. Phenol correction was done against a solution containing $2 \mathrm{~mL}$ of water added by $1 \mathrm{ml}$ of phenol $5 \%$ and $5 \mathrm{~mL}$ of sulphuric acid. The glucose assay was also prepared with the known concentrations from $0,025 \mathrm{~g} / \mathrm{L}$ to $0,1 \mathrm{~g} / \mathrm{L}$. A standard curve of corresponding absorbance was drawn.

An enzymatic method was used to determine biochemically different sugars, like sucrose, glucose, and fructose with enzymatic kits (Biosentec, France).

The concentration of D-glucose/D-fructose/sucrose in the sample, used in the assay procedure, had to be between 0.05 and $0.8 \mathrm{~g} / \mathrm{L}$, wavelength $340 \mathrm{~nm}$, optical path $1 \mathrm{~cm}$, and temperature $20-37 \circ \mathrm{C}$.

2.7. Total Ash Content Assay. Three grams of each sample was weighted in crucibles which has to be preashed and was put in muffle furnace at $550^{\circ} \mathrm{C}$ for 5 hours. After incineration, the crucibles were left in desiccator for $30 \mathrm{mn}$ and then weighed. The content of total ash is calculated as percentage relative to dry matter.

2.8. Polyphenol Content Assay. Five grams of each powder was mixed with 2 times $50 \mathrm{~mL}$ of methanol/water $(80 / 20)$ with Ultra-Turrax for $7 \mathrm{~min}$ and then passed to centrifugation. The supernatant was transferred into the flasks and completed at $100 \mathrm{~mL}$. The total phenolic content was evaluated by using the Folin-Ciocalteu method. Twenty microliters of the extract was mixed with $100 \mu \mathrm{L} 1: 10$ diluted Folin-Ciocalteu reagent and $80 \mu \mathrm{L}$ sodium carbonate solution $(75 \mathrm{~g} / \mathrm{L})$ in wells of 96 -well microplate. After $1 \mathrm{~h}$ of remaining in the darkness and at room temperature, the absorbance was measured at $740 \mathrm{~nm}$ in the microplate reader. Gallic acid monohydrate $(1.05-21 \mathrm{mg} / 100 \mathrm{~mL})$ was used as the standard for the calibration and the construction of a linear regression line and water as blank; the total phenolic content was calculated as gallic acid equivalents in $\mathrm{mg} / \mathrm{L}$ or $\mathrm{g} / 100 \mathrm{~g}$ of matrix. Polyphenols quantification was performed in triplicate.

2.9. DPPH Radical Scavenging. The radical scavenging activity of extract was evaluated by a modified version of the method, proposed by Brand and Williams, converted into micro method. More specifically, a stock methanolic solution $(10 \mathrm{mg} / \mathrm{mL})$ of each extract was diluted to prepare the samples, ranging from 20 to $0.625 \mu \mathrm{g} / \mathrm{mL}$ and then, $50 \mu \mathrm{L}$ of each sample was pipetted into 96-well plates in triplicate and was assessed in every well $50 \mu \mathrm{L}$ of DPPH solution ( $0.5 \mathrm{mM}$ in methanol). Plates were placed in dark for $40 \mathrm{~min}$ at room temperature and then the absorbance was measured at $510 \mathrm{~nm}$. The results were plotted as the percentage of remaining $\mathrm{DPPH}$ (\% I DPPH) against the concentration $(\mu \mathrm{g} / \mathrm{mL})$ of the added samples.

$$
\% \mathrm{I} \mathrm{DPPH}=\left[\frac{A \text { blank }-A \text { sample }}{A \text { blank }}\right] * 100,
$$


where $A$ sample $=$ absorbance of the sample and $A$ blank $=$ absorbance of the blank.

Results are expressed as inhibitory concentration (IC50) which corresponds to extract concentration $(\mu \mathrm{g} / \mathrm{mL})$ or $\mathrm{g} / 100 \mathrm{~g}$ of matrix, required to quench $50 \%$ of the initial DPPH radicals under the given experimental conditions.

2.10. Conventional Soxhlet Extraction (CSE). For CSE, $100 \mathrm{~g}$ of carob was placed in the extraction chamber of a Soxhlet apparatus $(125 \mathrm{~mL}$ capacity). The cellulose thimble was plugged with cotton in order to avoid transfer of sample particles in the distillation flask. The Soxhlet apparatus, fitted with a condenser, was placed on a $2000 \mathrm{~mL}$ boiling flask, containing $1000 \mathrm{~mL}$ of solvent. Extraction was performed using a solid to liquid ratio of 1 to $10(\mathrm{~m} / \mathrm{v})$, for 8 hours. After extraction, the extract was concentrated until being dried by solvent evaporation under vacuum (Laborota 4001, Heidolph, Germany) and finally, it was conserved at $4^{\circ} \mathrm{C}$ before analysis. Detailed analysis has been explained and detailed in our previous publication (Meullemiestre et al. 2016) [49].

2.11. Lipid Analysis Composition. Lipid classes in oil extract were determined by high-performance thin-layer chromatography (HPTLC), using two different development chromatography methods to separate polar and neutral classes. Lipids were quantified by a CAMAG 3 TLC scanning densitometer (CAMAG, Muttenz, Switzerland) with identification of the classes against the known polar and neutral lipid standards. Lipid classes of each carob extract were identified and quantified against those of corresponding lipid standards. Detailed analysis has been explained and detailed in our previous publication Meullemiestre et al. 2016 [49].

2.12. Preparation of Fatty Acids Methyl Esters (FAMEs). FAMEs were prepared from the lipid extract, using acidcatalyzed transmethylation. $1 \mathrm{~mL}$ of methanolic sulphuric acid (5\%) solution was added to a specific amount of extracted carob oil. Triheptadecanoin (C17:0 TAG) was used as internal standard. Detailed analysis has been explained and detailed in our previous publication (Meullemiestre et al.) 2016 [49].

2.13. FAMEs Analysis. Fatty acids methyl esters were separated, identified, and quantified by gas chromatography, coupled with flame ionization detector (GC-FID). The instrument Agilent (Kyoto, Japan) was equipped with a BDEN14103 capillary column $30 \mathrm{~m} \times 320 \mu \mathrm{m} \times 0.25 \mu \mathrm{m}$ (Agilent). FAMEs were identified by retention time and comparison with purified FAME standards (Sigma Co., USA). Detailed analysis has been explained and detailed in our previous publication (Meullemiestre et al.) 2016 [49].

2.14. Sensory Analysis. Sensory analyses were conducted by a panel consisting of 18 graduate students from the University of Avignon, France. The subjects were seated in sensory booths with appropriate ventilation and lighting. The samples were presented to each panelist on white polystyrene plates. Subjects were instructed to place the stimuli on the
TABle 1: Physicochemical characterization of initial and roasted carob pod powder.

\begin{tabular}{lcccc}
\hline & $\mathrm{C} 0$ & $\mathrm{C} 1$ & $\mathrm{C} 2$ & $\mathrm{C} 3$ \\
\hline Moisture (\%) & $9 \pm 0.8$ & $6.3 \pm 0.6$ & $4.3 \pm 0.8$ & $3.5 \pm 0.7$ \\
$\mathrm{Aw}$ & $0.6 \pm 0.05$ & $0.2 \pm 0.05$ & $0.155 \pm 0.05$ & $0.14 \pm 0.05$ \\
$\mathrm{pH}$ & $5.6 \pm 0.1$ & $5.5 \pm 0.1$ & $5.4 \pm 0.1$ & $5.5 \pm 0.1$ \\
Total sugars (\%) & $43.4 \pm 0.5$ & $36 \pm 0.5$ & $27.3 \pm 0.4$ & $15.4 \pm 0.5$ \\
Sucrose (\%) & $27.6 \pm 0.2$ & $23.3 \pm 0.2$ & $10.5 \pm 0.2$ & $6.2 \pm 0.2$ \\
Glucose (\%) & $4.1 \pm 0.2$ & $2.6 \pm 0.2$ & $2.5 \pm 0.2$ & $1.6 \pm 0.2$ \\
Fructose (\%) & $5.9 \pm 0.2$ & $4.0 \pm 0.2$ & $3.1 \pm 0.2$ & $1.8 \pm 0.2$ \\
Ash & $3,22 \pm 0,3$ & $3,78 \pm 0,3$ & $4,1 \pm 0,3$ & $4,92 \pm 0,3$ \\
Coloration $C^{*}$ & $22.6 \pm 0.5$ & $23.1 \pm 0.5$ & $20.7 \pm 0.5$ & $16.9 \pm 0.5$ \\
\hline
\end{tabular}

tongue and rub the tongue against the palate. Tap water was supplied to the panelists for rinsing between samples. The following attributes were evaluated for the three products: roasted aroma, cacao aroma, sweet taste, astringent taste, and caramelised taste. For overall quality, the scale range was from 0 to 10 . On this scale, a score of 0 represented the weakest attribute and a score of 10 represented the strongest one. Detailed analysis has been explained and detailed in our previous publication (Pingret et al. 2011) [47].

\section{Results and Discussion}

By roasting the carob pulp under different conditions of roasting time-roasting temperature combinations, the obtained product can have different specifications such as modulated color, aroma, and taste. Studying the effects of these parameters and the physicochemical ones allows the food industries to control the process for obtaining the best products.

Roasting has been done at different temperatures for the same processing time $(20 \mathrm{~min})$ to obtain different products in terms of color, aroma, and taste. The initial grinded carob pulp, $\mathrm{C} 0$, was just dried at $110^{\circ} \mathrm{C}$ to obtain the first product, $\mathrm{Cl}$, which has a lighter color and the specific initial carob odour. At $130^{\circ} \mathrm{C}$, carob sugars undergo the Maillard reaction and the caramelisation, producing a new product, $\mathrm{C} 2$, which is obviously different from the unroasted one. Roasting at high temperature $\left(150^{\circ} \mathrm{C}\right)$, the last product, $\mathrm{C} 3$, was completely dark as a result of producing brown pigments. The overall experimental plan is shown in Figure 2.

3.1. Comparison of Physiochemical Properties of Carob at Different Roasting Temperatures. Different parameters as moisture, water activity, total sugars, and different sugars as sucrose, glucose, and fructose have decreased when the temperature of roasting increases. The results are shown in Table 1.

The average moisture content of nonroasted carob powder samples was determined as $9 \%$ which reduced to $6.3 \%$, $4.3 \%$, and $3.5 \%$ after $20 \mathrm{~min}$ of roasting at $110^{\circ} \mathrm{C}, 130^{\circ} \mathrm{C}$, and $150^{\circ} \mathrm{C}$, respectively. These values are intermediate between carob moisture values of Sahin et al. 2009 [50] and the values reported by Vitali Cepo et al. 2014 [51]. This can be due to 


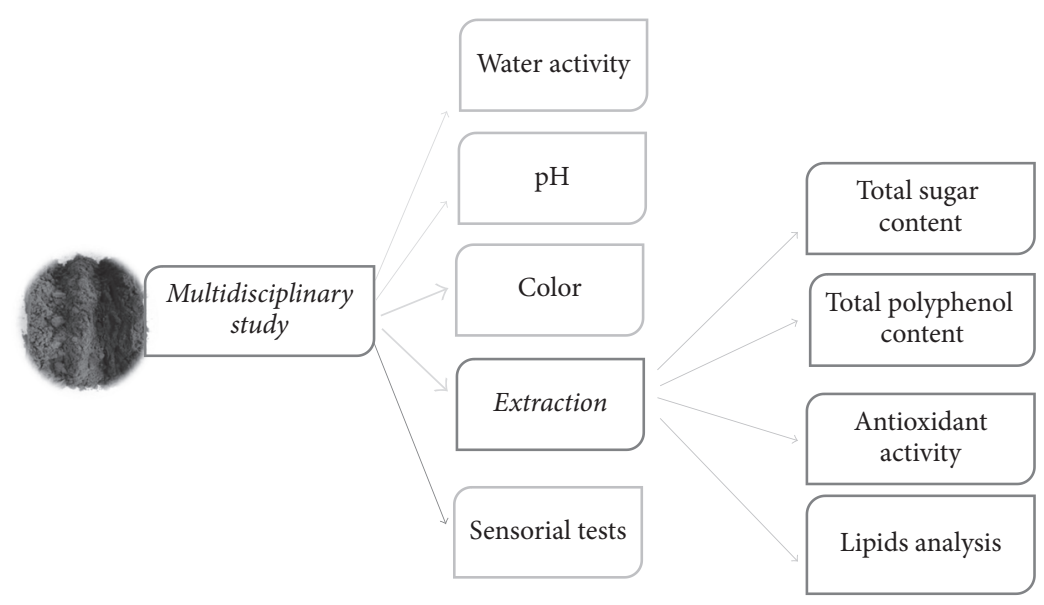

FIGURE 2: Multidisciplinary study of roasting carob pulp.

the fruit variety and also to ripening stage when harvested. $\mathrm{C} 1$ has been dried and the water activity has decreased so much regarding $\mathrm{C} 0 . \mathrm{C} 2$ and $\mathrm{C} 3$ have approximated values of moisture and water activity due to the maximal evaporation of water. Reduction in the moisture content allows an easier milling and can extend the shelf-life of the carob powder as explained by Iipumbu [7]. In Table 1, it was also observed that water activity decreased as the roasting temperature increased as revealed by Yousif and Alghzawi 2000 [14]. The aw value (water activity), important parameter in browning reactions, gives information about chemical, physical, and microbiological product quality. Sahin et al., 2009 [50], have reported that $\mathrm{pH}$ decreases gradually with increasing temperature after $20 \mathrm{mn}$. $\mathrm{pH}$ value of the different samples decreases slowly when increasing roasting because of the caramelisation reaction releasing acidity, making the solution sour, and also the Maillard reaction products (MRP) [52].

Maillard reaction requires temperatures superior to $50^{\circ} \mathrm{C}$ and it is favoured when $\mathrm{pH}$ is around 4-7 while caramelisation proceeds at temperatures superior to $120^{\circ} \mathrm{C}$ and $\mathrm{pH}$ between 3 and 9 [52]. Unroasted carob undergoes drying with Maillard reaction at $\mathrm{pH} 5.5$ at $110^{\circ} \mathrm{C}$ to obtain $\mathrm{C} 1$, when $\mathrm{C} 2$ and C3 have both caramelisation and Maillard reaction.

Carob is sweet product due to its content of total sugars; mostly sucrose, glucose, and fructose decrease more and more with the temperature and the time of roasting. Roasted carob C3 is less sweet than the natural carob. The ratio of individual sugars to total sugar in carob was similar in the three-roasted carob. The sweetness values decreased as the roasting temperature increased. Heating sucrose in concentrated solution at high temperature leads to hydrolysis and production of fructose and glucose. These components participate in different reactions of caramelisation to form stable 5-hydroxymethylfurfural (HMF) [53]. The Maillard reaction is triggered between glucose and an amino acid and a multitude of reactions causing the formation of MRPs as furfurals, hydroxymethylfurfural (HMF), and final products, melanoidins (brown nitrogenous pigments) [54]. At $110^{\circ} \mathrm{C}$, $\mathrm{C} 0$ is dried and the reaction of Maillard begins at the first five

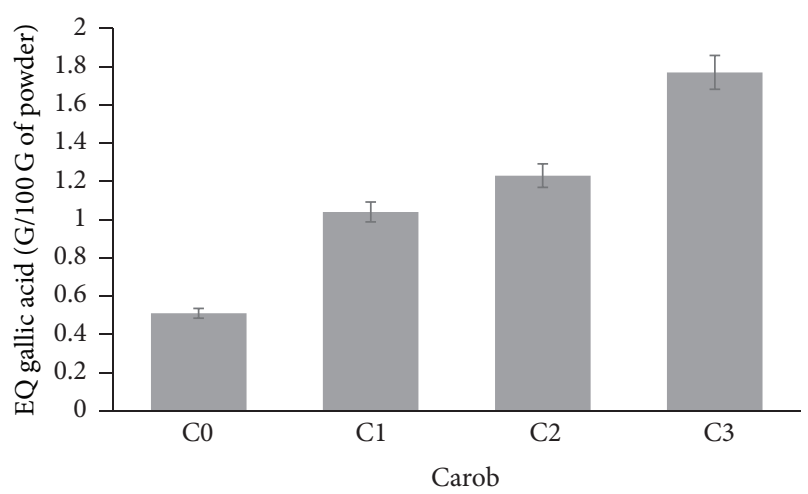

FIGURE 3: Total polyphenol content (TPC).

minutes. At $130^{\circ} \mathrm{C}$ and $150^{\circ} \mathrm{C}$, raw carob undergoes Maillard and caramelisation reaction causing brown pigments giving specific color to each product. Little increase of minerals content in the four products is due to the calculation of the content to the dry matter.

3.2. Comparison of Antioxidant Properties of Carob at Different Roasting Temperatures. Phenolic compounds are of high interest as alternative for synthetic antioxidant to prevent lipid peroxidation in food products. Total polyphenol content (TPC) extracted from carob powder by Ultra-Turrax $(2 *$ $50 \mathrm{~mL}, 80 \%$ methanol, $2 * 7 \mathrm{~min}$ ) is shown in Figure 3 .

The obtained TPC increased by increasing the roasting temperature of $110^{\circ} \mathrm{C}, 130^{\circ} \mathrm{C}$, and $150^{\circ} \mathrm{C}$, respectively. $\mathrm{C} 0$ contains $0.51 \%$ a percentage in concordance with Sahin et al. 2009 [50]. Phenolic content, obtained from soluble fraction, increases with increasing temperature as revealed by Vitali Cepo et al. 2014 [51] clearly indicating that, during roasting, polyphenols are released from certain polymers making them available for absorption. They also have shown that, after prolonged roasting longer than $15 \mathrm{~min}$ at $150^{\circ} \mathrm{C}$ or $30 \mathrm{mn}$ at $130^{\circ} \mathrm{C}$, the increase of the total polyphenolic compounds in soluble fraction and antioxidant activity is stopped. C1, $\mathrm{C} 2$, and $\mathrm{C} 3$ have been roasted at $110^{\circ} \mathrm{C}, 130^{\circ} \mathrm{C}$, and $150^{\circ} \mathrm{C}$, 


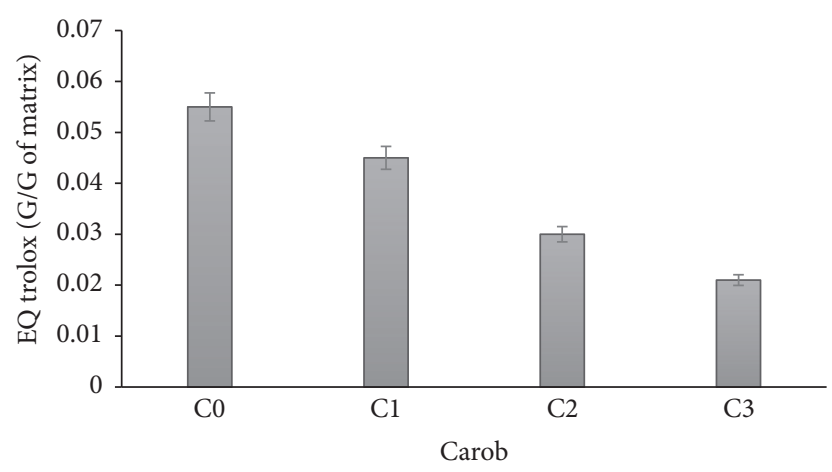

FIGURE 4: IC50 values determined by the DPPH assay for carob extracts obtained by Ultra-Turrax.

respectively, during $20 \mathrm{mn}$; it could be the necessary time for obtaining the higher amount of polyphenols.

The antioxidant potential of the extracts is shown in Figure 4. The DPPH tests provided information about the activities of the compounds with stable free radicals; DPPH effect was assumed to be due to their hydrogen donating ability. Higher IC50 values signify less antioxidant activity and vice versa.

Comparing TPC to AA (antioxidant activity) data obtained from the extracts, it can be observed that AA was proportional to TPC. A high antioxidant activity is expected to be caused by its high content in polyphenols. Sahin et al., 2009 [50], have investigated chemical changes of total phenolic content, total antioxidant activity, and browning index on different roasted carob powders; they reported that, during the roasting process, important chemical reactions including sugar caramelisation and Maillard reaction took place, which cause significant changes in product quality. Many studies have focused on the properties of Maillard reaction products (MRPs), particularly on the antioxidant activity of MRPs in food products.

Folin-Ciocalteu reagent detects all phenolic groups present in sample, containing the naturally occurring phenolic and also the newly formed compound during roasting process. MRPs with phenolic type structure can also be determined by the Folin method. The increase in the TPC of the carob powders could be explained by the formation of MRPs with phenolic type structures during the process. The increase in the antioxidant activity of carob with increasing roasting degree was attributed to Maillard reaction products (MRPs) formed during roasting of carob like roasting coffee [55].

Since no standardized method is available to evaluate the antioxidant capacity of plant extracts and numerous methods have been employed to estimate the antioxidant potential, in the present study, DPPH radical scavenging effect was used to assess the antioxidant activity of carob powder before and after roasting.

The antioxidant activity (AA) of the extracts is due to the presence of phenolic compounds [55]. The antioxidant activities of the extracts at different roasting temperatures were measured. According to the results, the extracts of the high roasting temperature, $\mathrm{C} 3$, had a higher antioxidant activity and a higher quantity of polyphenols. Maillard reaction and caramelisation products improve antioxidant activity due to the liberation of HMF and also for the formation of melanoidins [50]. Therefore, these results are in concordance with the results of Sahin et al. 2009 [50] and prove that antioxidant activity of the samples increases as the roasting temperature goes up. Time of roasting is an important parameter for controlling the antioxidant activity as shown by Sahin et al. [50,51] which concluded that roasting carob at $130^{\circ} \mathrm{C}$ for $30 \mathrm{~min}$ can be proposed as the procedure of choice for obtaining carob powder with high antioxidant activity.

\subsection{Comparison of Color of Carob at Different Roasting Tem-} peratures. The different roasted carobs were also compared by their physical characteristics as color (Table 1). Heating sugars and sugar rich food causes reactions inducing color and flavour. $\mathrm{C} 0$ has lighter color than $\mathrm{Cl}$, and from $130^{\circ} \mathrm{C}$, the color became brown and then darker brown than the initial color as presented in Figure 5. In their investigation, Vitali Cepo et al., 2014 [51], have revealed that the highest formation of brown pigments was noticed during the first five minutes of thermal treatment at different applied temperature.

3.4. Quantitative and Qualitative Analysis of Lipids Classes. Roasted and unroasted carob were extracted with hexane for 8 hours by Soxhlet extraction. The extracts were centrifuged and evaporated. The obtained oil was analyzed by highperformance thin-layer chromatography (HPTLC) to gain the lipid classes. For obtaining fatty acid profiles, the gas chromatography coupled with a flame ionization detector (GC/FID) was used after transmethylation.

Carob oils were classified into two categories according to their polarities: neutral lipids and polar lipids. Carob oils tend to accumulate neutral lipids, including monoacylglycerol (MAG), diacylglycerol (DAG), triacylglycerol (TAG), free fatty acids (FFA), and alkyl chain. Using the highperformance thin-layer chromatography (HPTLC), neutral lipids of the extracted carob oils were separated and quantified. For all extracted carob oils, the distribution of the different lipid classes was obtained by the external calibration. To quantify the percentage of the lipid classes, four standards were used, including monoglycerides (MAG), diacylglycerol (DAG), triglycerides (TAG), and free fatty acids (FFA) (C18), and deposited on the HPTLC plate. As shown in Figure 6, MAG and TAG were not found in all extracts. DAG and FFA are the major components which is due to drastic conditions of drying and roasting which induce oxidation and hydrolysis of TAG to DAG and MAG [56].

As shown in Figure 6, lipid yields decrease as the roasting temperature increases; it is due to the oxidation induced by the high temperature and the formation of products when reacting with amino acids or proteins causing brown pigments, similar to melanoidins $[7,57]$. Fatty acid profiles (Figure 6) show that oleic acid (C18:1), linoleic acid (C18:2n6), and palmitic acid (C16:0) were mainly present in carob oil and represented at least $90 \%$ of the total extract (about 50\% of C18:1, 20\% of C18:2n6, and 20\% of C16:0). It was also observed that palmitoleic acid (C16:1) and stearic acid were in 
Comparison of powders depending on their hues $a^{*} b^{*}$

\begin{tabular}{|c|c|c|c|}
\hline & $L$ & $a$ & $b$ \\
\hline$\overline{\mathrm{C} 0}$ & 63,46 & 7,06 & 21,46 \\
\hline $\mathrm{C} 1$ & 56,70 & 8,76 & 21,43 \\
\hline $\mathrm{C} 2$ & 49,13 & 8,50 & 18,86 \\
\hline $\mathrm{C} 3$ & 37,24 & 7,94 & 14,93 \\
\hline
\end{tabular}

Chromameter Konica Minolta CR-400/CR-410

Powders of Carob in function of their colorimetric coordinates $L^{*} a^{*} b^{*}$

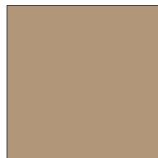

$\mathrm{CO}$

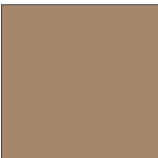

C1

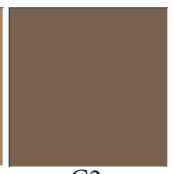

$\mathrm{C} 2$

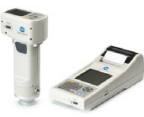

Comparison of powders depending on their hues $a^{*} b^{*}$

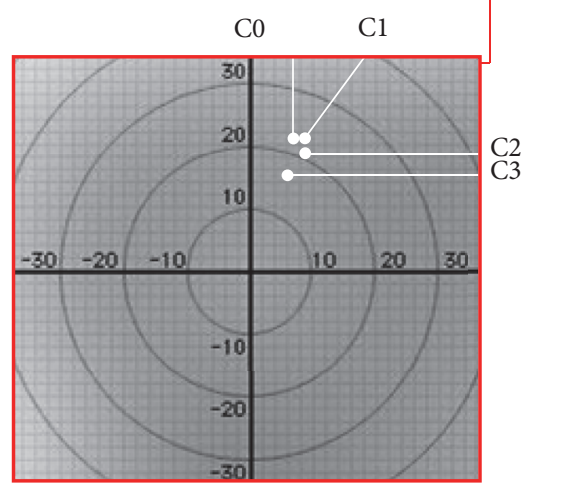

FIGURE 5: Color assessment of initial and roasted carob pod powders.

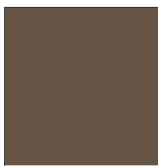

C3
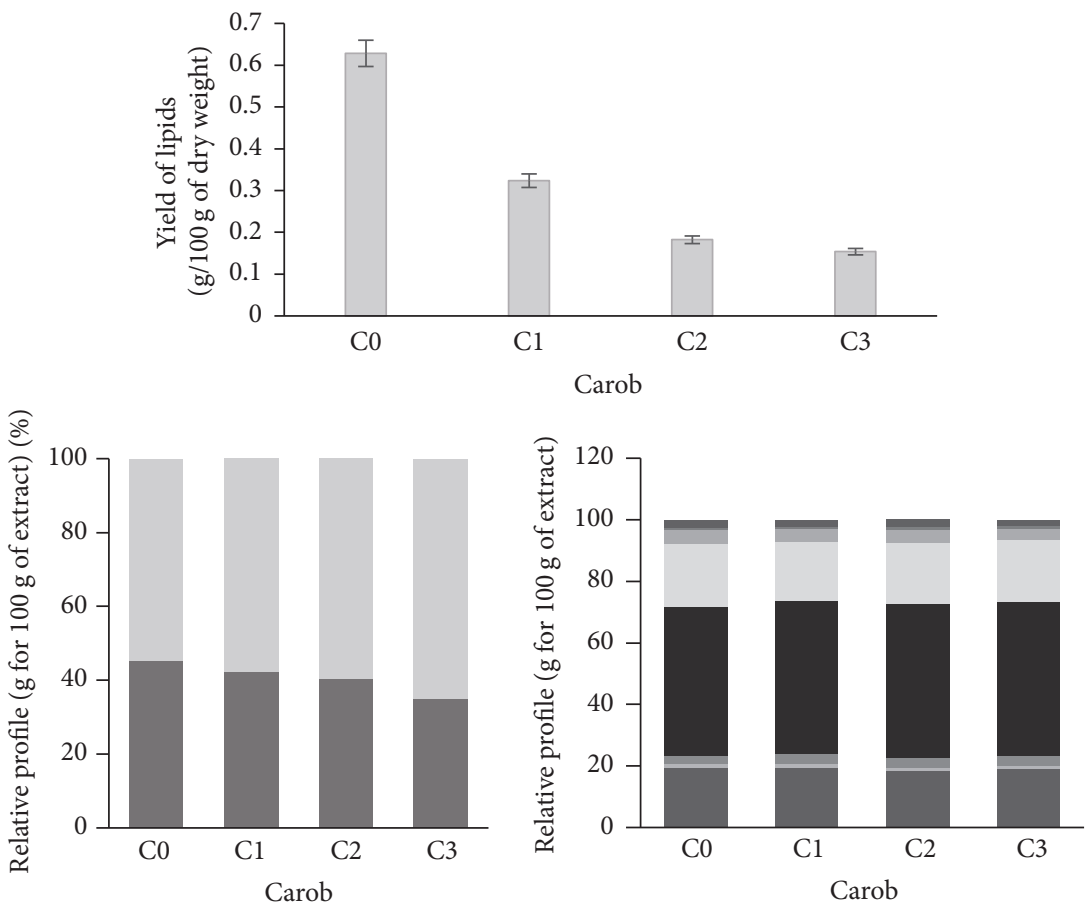

FFAs

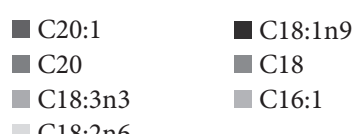

C18.2n6

Figure 6: Lipid composition.

minor amounts. The detailed composition for each extract is reported in Figure 6. C0 contains $0,8 \%$ of lipids, a very good amount of fat compared to cocoa. By roasting, C1, C2, and C3 have less fat, $0,4 \%$; carob powder can be the best dietary substitute of cocoa $[10,14]$.
3.5. Sensorial Tests. Roasted carob has potentialities to be a dietary replacement of cocoa due to its lower content in fat and its good content in dietary fiber [10]. Sensorial tests can predict the consumer feedback about an unknown product cocoa replacement. 


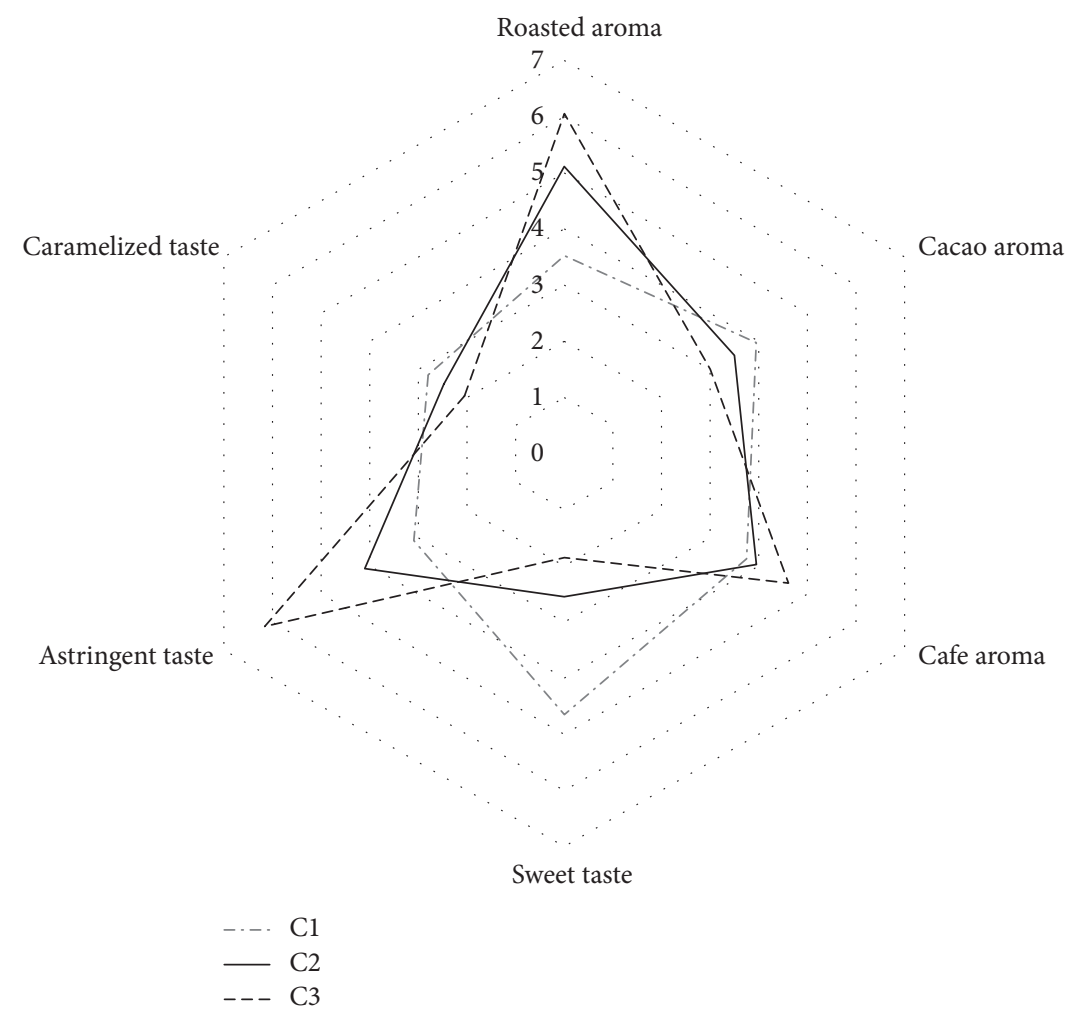

FIGURE 7: Sensorial analysis.

The results of sensorial tests for the three carobs are correlated with their physical characteristics in Figure 7. The panelists found $\mathrm{Cl}$ to be sweeter due to its contents in sugars and mainly in sucrose which can induce reducing the added processing sugars in food industry, have more caramel-like taste, and have more cacao-like aroma than the other ones [14]. They also recognized the most astringent taste, coffeelike aroma, and roasted aroma in C3. They found that C2 has astringent taste and roasted aroma.

Berna et al. [33] recognized that the undesirable smell produced by isobutyric acid in carob can be reduced through roasting process and losing that compound and the higher loss of isobutyric acid will bring a higher sensory quality of the carob powder, which is a factor to consider when establishing the roasting time. The volatile fraction of carob bean pulp during a roasting process has been also analyzed by Cantalejo 1997 [58] and 137 components were identified. 91.4\% of the identified compounds in raw carob contained acids, alcohols, and aldehydes; during the roasting process, the amount of these compounds decreased about $51.2 \%$ of the total compounds.

\section{Conclusion}

The effect of temperature on physicochemical parameters, antioxidant activity, lipid composition, and sensory analysis of unroasted and roasted carob powders were compared in this study. The initial carob powder $(\mathrm{C} 0)$ was dried at $110^{\circ} \mathrm{C}$ $(\mathrm{C} 1), 130^{\circ} \mathrm{C}(\mathrm{C} 2)$, and $150^{\circ} \mathrm{C}(\mathrm{C} 3)$ for the same processing time $(20 \mathrm{~min})$. The $\mathrm{pH}$ of the roasted products decrease just a little but the color of the products became darker, the average moisture content of C0 was reduced from $9 \%$ to $6.3 \%$ and $4.3 \%$ and $3.5 \%$, and the water activity and the sweetness values decreased as the roasting temperature was increased. Total polyphenol content and the antioxidant activity which is due to the presence of the phenolic compounds, Maillard reaction, and caramelisation products increased by increasing the roasting temperature. Carob oil analysis showed that lipid yields decreased at higher roasting temperatures. They tended to accumulate neutral lipids, including monoacylglycerol, diacylglycerol, triacylglycerol, free fatty acids, and alkyl chain. Diacylglycerol and free fatty acids were the major components of all the extracted carob oils, with a decrease in the percentage of diacylglycerol and an increase in the percentage of free fatty acids as the roasting temperature increased. Fatty acid profiles showed that oleic acid, linoleic acid, and palmitic acid were mainly present in carob oil and represented at least $90 \%$ of the total extract. The panelists found $\mathrm{Cl}$ to be sweeter, have more caramel-like taste, and have more cacao-like aroma than the other ones and the most astringent taste, coffee-like aroma, and roasted aroma in C3. Roasted carob powder could be used as food ingredient in different kinds of food and also as dietary supplement.

\section{Additional Points}

Practical Applications. Carob pulp which was byproduct with little value is becoming a real raw material for food ingredients for its organoleptic properties, aroma, color, and taste, and also for its dietary quality. Having a cocoa-like 
aroma of roasted carob, carob pulp is mainly roasted and grinded to powder to be used as cocoa substitute. This study shows that by adding a food process such as roasting in the whole chain we could change a byproduct to raw material with high value for producing food ingredients. It is a real success story that could be applied for other products.

\section{Conflicts of Interest}

The authors declare that there are no conflicts of interest regarding the publication of this paper.

\section{References}

[1] D. Hillcoat, G. Lewis, and B. Verdcourt, "A New Species of Ceratonia (Leguminosae-Caesalpinioideae) from Arabia and the Somali Republic," Kew Bulletin, vol. 35, no. 2, p. 261, 1980.

[2] R. W. Owen, R. Haubner, W. E. Hull et al., "Isolation and structure elucidation of the major individual polyphenols in carob fibre," Food and Chemical Toxicology, vol. 41, no. 12, pp. 1727-1738, 2003.

[3] P. Barracosa, J. Osório, and A. Cravador, "Evaluation of fruit and seed diversity and characterization of carob (Ceratonia siliqua L.) cultivars in Algarve region," Scientia Horticulturae, vol. 114, no. 4, pp. 250-257, 2007.

[4] S. Naghmouchi, M. L. Khouja, A. Romero, J. Tous, and M. Boussaid, "Tunisian carob (Ceratonia siliqua L.) populations: Morphological variability of pods and kernel," Scientia Horticulturae, vol. 121, no. 2, pp. 125-130, 2009.

[5] A. Durazzo, V. Turfani, V. Narducci, E. Azzini, G. Maiani, and M. Carcea, "Nutritional characterisation and bioactive components of commercial carobs flours," Food Chemistry, vol. 153, pp. 109-113, 2014.

[6] L. Seczyk, M. Swieca, and U. Gawlik-Dziki, "Effect of carob (Ceratonia siliqua L.) flour on the antioxidant potential, nutritional quality, and sensory characteristics of fortified durum wheat pasta," Food Chemistry, vol. 194, pp. 637-642, 2016.

[7] L. Iipumbu, Compositional analysis of locally cultivated carob (Ceratonia siliqua) cultivars and development of nutritional food products for a range of market sectors, University of Stellenbosch, Stellenbosch, 2008.

[8] I. Battle and J. Tous, "J. Carob tree. Ceratonia siliqua L," in Promoting the Conservation and use of Under-utilised and Neglected Crops, Institute of Plant Genetics and Crop Plant Research and Gatersleben/International Plant Genetic Resource Institute, Rome, Italy, 1997.

[9] M. Khlifa, A. Bahloul, and S. Kitane, "Determination of chemical composition of carob pod (Ceratonia siliqua L) and its morphological study," Journal of Materials and Environmental Science, vol. 4, no. 3, pp. 348-353, 2013.

[10] S. M. Nasar-Abbas, Z. e-Huma, T.-H. Vu, M. K. Khan, H. Esbenshade, and V. Jayasena, "Carob Kibble: A Bioactive-Rich Food Ingredient," Comprehensive Reviews in Food Science and Food Safety, vol. 15, no. 1, pp. 63-72, 2016.

[11] M. G. Bernardo-Gil, R. Roque, L. B. Roseiro, L. C. Duarte, F. Gírio, and P. Esteves, "Supercritical extraction of carob kibbles (Ceratonia siliqua L.)," Journal of Supercritical Fluids, vol. 59, pp. 36-42, 2011.

[12] L. B. Roseiro, C. S. Tavares, J. C. Roseiro, and A. P. Rauter, "Antioxidants from aqueous decoction of carob pods biomass
(Ceretonia siliqua L.): Optimisation using response surface methodology and phenolic profile by capillary electrophoresis," Industrial Crops and Products, vol. 44, pp. 119-126, 2013.

[13] E. Karababa and Y. Coşkuner, "Physical properties of carob bean (Ceratonia siliqua L.): An industrial gum yielding crop," Industrial Crops and Products, vol. 42, no. 1, pp. 440-446, 2013.

[14] A. K. Yousif and H. M. Alghzawi, "Processing and characterization of carob powder," Food Chemistry, vol. 69, no. 3, pp. 283287, 2000.

[15] F. A. Ayaz, H. Torun, S. Ayaz et al., "Determination of chemical composition of anatolian carob pod (Ceratonia siliqua L.): sugars, amino and organic acids, minerals and phenolic compounds," Journal of Food Quality, vol. 30, no. 6, pp. 10401055, 2007.

[16] D. B. Hmamou, R. Salghi, A. Zarrouk et al., "Carob seed oil: an efficient inhibitor of C38 steel corrosion in hydrochloric acid," International Journal of Industrial Chemistry, vol. 3, no. 1, article no. 25, pp. 1-9, 2012.

[17] Y. Ercan, T. Irfan, and K. Mustafa, "Optimization of ethanol production from carob pod extract using immobilized Saccharomyces cerevisiae cells in a stirred tank bioreactor," Bioresource Technology, vol. 135, pp. 365-371, 2013.

[18] U. Cakilcioğlu and I. Turkoğlu, "Plants and fruits used for cholesterol treatment by the folk in Elazig," Phytologia Balcanica, vol. 13, pp. 239-245, 2007.

[19] N. A. Jaradat, Medical Plants Utilized in Palestinian Folk Medicine for Treatment of Diabetes Mellitus and Cardiac Diseases, Al-Aqsa University, 2005.

[20] E. Lev and Z. Amar, "Ethnopharmacological survey of traditional drugs sold in the Kingdom of Jordan," Journal of Ethnopharmacology, vol. 82, no. 2-3, pp. 131-145, 2002.

[21] H. Loeb, Y. Vandenplas, P. Würsch, and P. Guesry, "Tannin-Rich carob pod for the treatment of acute-onset diarrhea," Journal of Pediatric Gastroenterology and Nutrition, vol. 8, no. 4, pp. 480485, 1989.

[22] B. Kivçak, B. Mert, and H. T. Öztürk, "Antimicrobial and cytotoxic activities of Ceratonia siliqua L. extracts," Turkish Journal of Biology, vol. 26, pp. 197-200, 2002.

[23] A. Ben Hsouna, A. S. Alayed, and E. M. Abdallah, "Evaluation of antimicrobial activities of crude methanolic extract of pods of Ceratonia siliqua L. against some pathogens and spoilage bacteria," African Journal of Microbiology Research, vol. 6, no. 14, pp. 3480-3484, 2012.

[24] B. Biner, H. Gubbuk, M. Karhan, M. Aksu, and M. Pekmezci, "Sugar profiles of the pods of cultivated and wild types of carob bean (Ceratonia siliqua L.) in Turkey," Food Chemistry, vol. 100, no. 4, pp. 1453-1455, 2007.

[25] T. Roukas, "Citric acid production from carob pod by solid-state fermentation," Enzyme and Microbial Technology, vol. 24, no. 12, pp. 54-59, 1999.

[26] J. Tous, A. Romero, J. F. Hermoso, A. Ninot, J. Plana, and I. Batle, "Agronomic and commercial performance of four Spanish carob cultivars," Hort Technology, vol. 19, no. 2, pp. 465470, 2009.

[27] P. A. Dakia, B. Wathelet, and M. Paquot, "Isolation and chemical evaluation of carob (Ceratonia siliqua L.) seed germ," Food Chemistry, vol. 102, no. 4, pp. 1368-1374, 2007.

[28] V. Rizzo, F. Tomaselli, A. Gentile, S. La Malfa, and E. Maccarone, "Rheological properties and sugar composition of locust bean gum from different carob varieties (Ceratonia siliqua L.)," Journal of Agricultural and Food Chemistry, vol. 52, no. 26, pp. 7925-7930, 2004. 
[29] C. Bengoechea, A. Romero, A. Villanueva et al., "Composition and structure of carob (Ceratonia siliqua L.) germ proteins," Food Chemistry, vol. 107, no. 2, pp. 675-683, 2008.

[30] M. D. Petit and J. M. Pinilla, "Production and purification of a sugar syrup from carob pods," LWT - Food Science and Technology, vol. 28, no. 1, pp. 145-152, 1995.

[31] I. Turhan, K. L. Bialka, A. Demirci, and M. Karhan, "Enhanced ethanol production from carob extract by Saccharomyces cerevisiae," in Proceedings of the American Society of Agricultural and Biological Engineers Annual International Meeting 2009, pp. 2040-2052, 2009.

[32] M. Germec, I. Turhan, M. Karhan, and A. Demirci, "Ethanol production via repeated-batch fermentation from carob pod extract by using Saccharomyces cerevisiae in biofilm reactor," Fuel, vol. 161, pp. 304-311, 2015.

[33] A. Berna, M. B. Pérez-Gago, V. G. Guardiola, D. Salazar, and A. Mulet, "Effect of Temperature on Isobutyric Acid Loss during Roasting of Carob Kibble," Journal of Agricultural and Food Chemistry, vol. 45, no. 10, pp. 4084-4087, 1997.

[34] L. Barroso, V. de Oliveira, A. Garcia, D. Doneda, L. Ouriques, and M. Vieira, "Physicochemical and Sensory Evaluation of Sandwich Cookies Made with Carob Powder," Advance Journal of Food Science and Technology, vol. 9, no. 4, pp. 290-295, 2015.

[35] C. S. Rosa, K. Tessele, R. C. Prestes, M. Silveira, and F. Franco, "Effect of substituting of cocoa powder for carob flour in cakes made with soy and banana flours," International Food Research Journal, vol. 22, no. 5, pp. 2111-2118, 2015.

[36] H. R. Oziyci, N. Tetik, I. Turhan et al., "Mineral composition of pods and seeds of wild and grafted carob (Ceratonia siliqua L.) fruits," Scientia Horticulturae, vol. 167, pp. 149-152, 2014.

[37] N. Tetik and E. Yüksel, "Ultrasound-assisted extraction of dpinitol from carob pods using Response Surface Methodology," Ultrasonics Sonochemistry, vol. 21, no. 2, pp. 860-865, 2014.

[38] A. Cháfer and A. Berna, "Study of kinetics of the d-pinitol extraction from carob pods using supercritical CO2," Journal of Supercritical Fluids, vol. 94, pp. 212-215, 2014.

[39] S. Kumazawa, M. Taniguchi, Y. Suzuki, M. Shimura, M.-S. Kwon, and T. Nakayama, "Antioxidant activity of polyphenols in carob pods," Journal of Agricultural and Food Chemistry, vol. 50, no. 2, pp. 373-377, 2002.

[40] F. Saura-Calixto, J. Pérez-Jiménez, S. Touriño et al., "Proanthocyanidin metabolites associated with dietary fibre from in vitro colonic fermentation and proanthocyanidin metabolites in human plasma," Molecular Nutrition and Food Research, vol. 54, no. 7, pp. 939-946, 2010.

[41] S. Klenow and M. Glei, "New insight into the influence of carob extract and gallic acid on hemin induced modulation of HT29 cell growth parameters," Toxicology in Vitro, vol. 23, no. 6, pp. 1055-1061, 2009.

[42] M. L. Croze and C. O. Soulage, "Potential role and therapeutic interests of myo-inositol in metabolic diseases," Biochimie, vol. 95, no. 10, pp. 1811-1827, 2013.

[43] C. Bañuls, S. Rovira-Llopis, R. Falcón et al., "Chronic consumption of an inositol-enriched carob extract improves postprandial glycaemia and insulin sensitivity in healthy subjects: A randomized controlled trial," Clinical Nutrition, vol. 35, no. 3, pp. 600-607, 2016.

[44] B. Ruiz-Roso, J. C. Quintela, E. de la Fuente, J. Haya, and L. Pérez-Olleros, "Insoluble carob fiber rich in polyphenols lowers total and LDL cholesterol in hypercholesterolemic sujects," Plant Foods for Human Nutrition, vol. 65, no. 1, pp. 50-56, 2010.
[45] H. J. F. Zunft, W. Lüder, A. Harde et al., "Carob pulp preparation rich in insoluble fibre lowers total and LDL cholesterol in hypercholesterolemic patients," European Journal of Nutrition, vol. 42, no. 5, pp. 235-242, 2003.

[46] N. Ortega, A. Macià, M.-P. Romero, J. Reguant, and M.-J. Motilva, "Matrix composition effect on the digestibility of carob flour phenols by an in-vitro digestion model," Food Chemistry, vol. 124, no. 1, pp. 65-71, 2011.

[47] D. Pingret, A.-S. Fabiano-Tixier, E. Petitcolas, J.-P. Canselier, and F. Chemat, "First investigation on ultrasound-assisted preparation of food products: sensory and physicochemical characteristics," Journal of Food Science, vol. 76, no. 2, pp. C287C292, 2011.

[48] B. Hill, T. Roger, and F. W. Vorragen, "Comparative analysis of the quantization of color spaces on the basis of the CIELAB color-difference formula," ACM Transactions on Graphics, vol. 16, no. 2, pp. 109-154, 1997.

[49] A. Meullemiestre, C. Breil, M. Abert-Vian, and F. Chemat, "Microwave, ultrasound, thermal treatments, and bead milling as intensification techniques for extraction of lipids from oleaginous Yarrowia lipolytica yeast for a biojetfuel application," Bioresource Technology, vol. 211, pp. 190-199, 2016.

[50] H. Sahin, A. Topuz, M. Pischetsrieder, and F. Özdemir, "Effect of roasting process on phenolic, antioxidant and browning properties of carob powder," European Food Research and Technology, vol. 230, no. 1, pp. 155-161, 2009.

[51] D. Vitali Cepo, A. Mornar, B. Nigović, D. Kremer, D. Radanović, and I. Vedrina Dragojević, "Optimization of roasting conditions as an useful approach for increasing antioxidant activity of carob powder," LWT-Food Science and Technology, vol. 58, no. 2, pp. 578-586, 2014.

[52] L. W. Kroh, "Caramelisation in food and beverages," Food Chemistry, vol. 51, no. 4, pp. 373-379, 1994.

[53] M. A. C. Quintas, T. R. S. Brandão, and C. L. M. Silva, "Modelling colour changes during the caramelisation reaction," Journal of Food Engineering, vol. 83, no. 4, pp. 483-491, 2007.

[54] M. Bastos, D. Monaro, and E. Siguemoto, "Maillard Reaction Products in Processed Food: Pros and Cons. Food industrial processes," in Methods and Equipment, B. Valdez, Ed., 2012.

[55] E. K. Bekedam, H. A. Schols, B. Cämmerer, L. W. Kroh, M. A. J. S. Van Boekel, and G. Smit, "Electron spin resonance (ESR) studies on the formation of roasting-induced antioxidative structures in coffee brews at different degrees of roast," Journal of Agricultural and Food Chemistry, vol. 56, no. 12, pp. 4597-4604, 2008.

[56] E. N. Frankel, "Recent advances in lipid oxidation," Journal of the Science of Food and Agriculture, vol. 54, no. 4, pp. 495-511, 1991.

[57] H. Nursten, The Maillard Reaction Chemistry, Biochemistry and Implications, The Royal Society of Chemistry, 2005.

[58] M. J. Cantalejo, "Effects of Roasting Temperature on the Aroma Components of Carob (Ceratonia siliqua L.)," Journal of Agricultural and Food Chemistry, vol. 45, no. 4, pp. 1345-1350, 1997. 

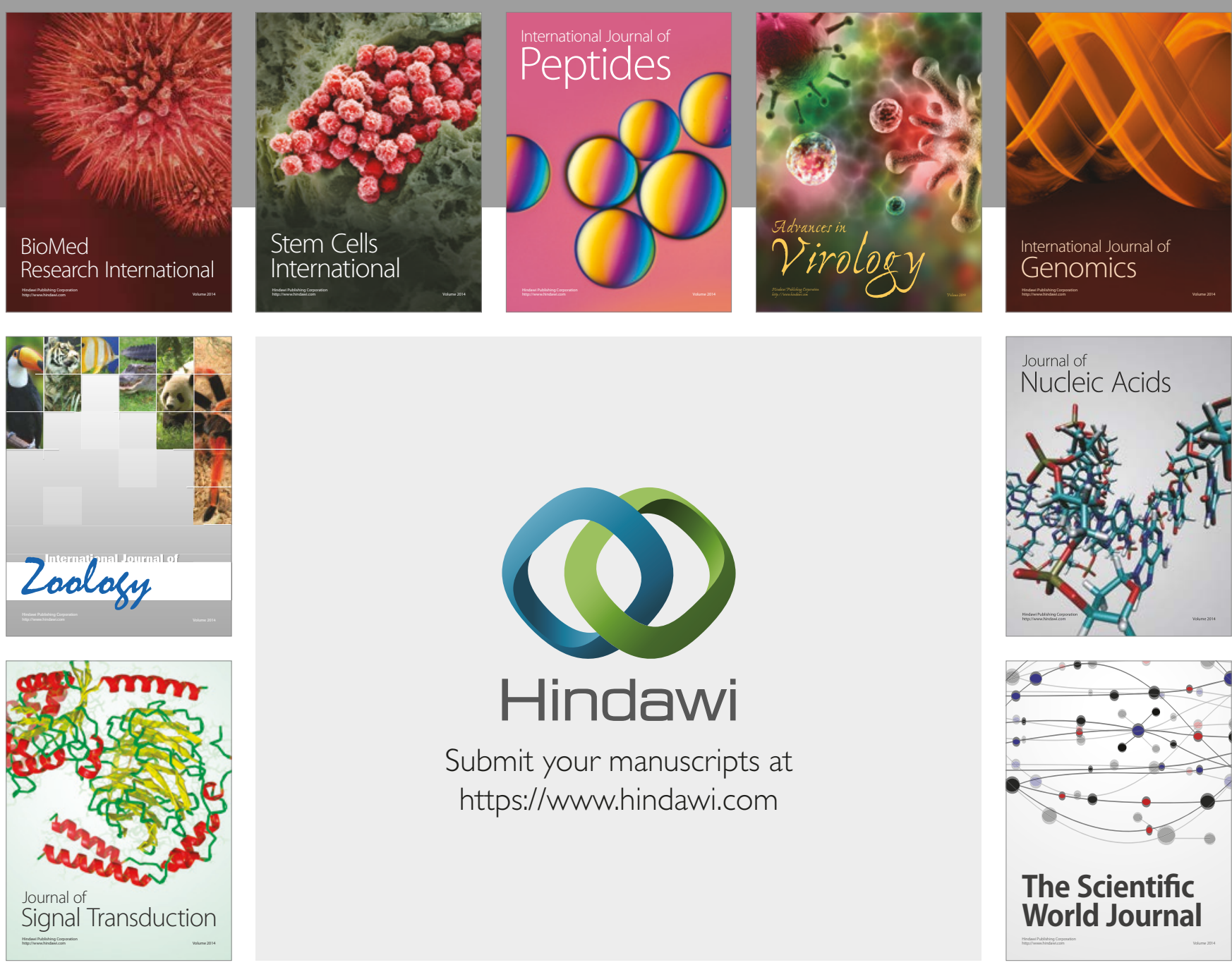

Submit your manuscripts at

https://www.hindawi.com
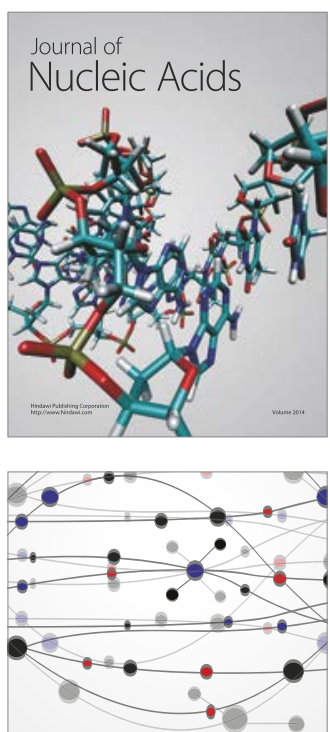

The Scientific World Journal

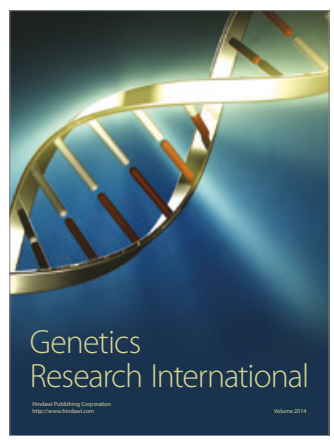

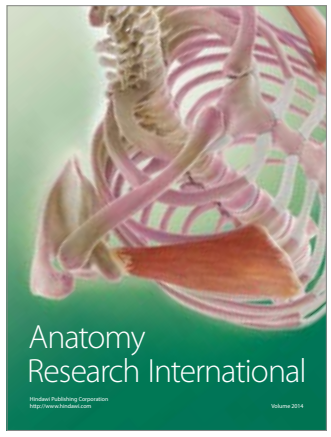

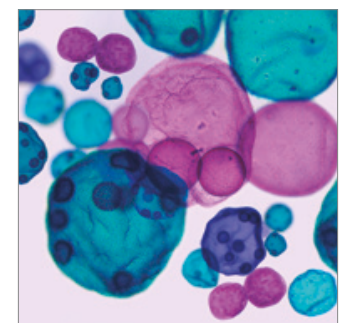

International Journal of Microbiology
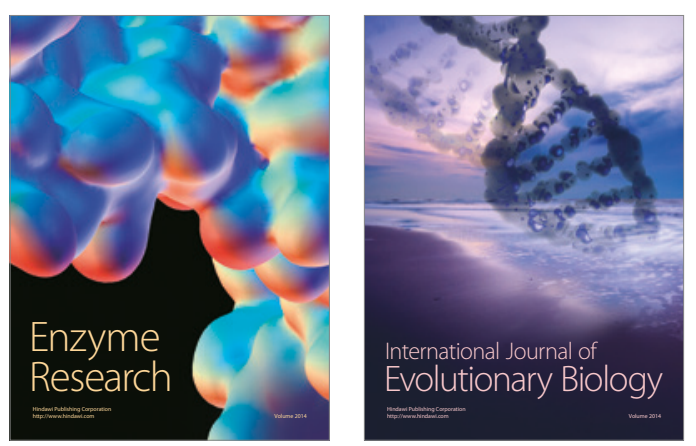
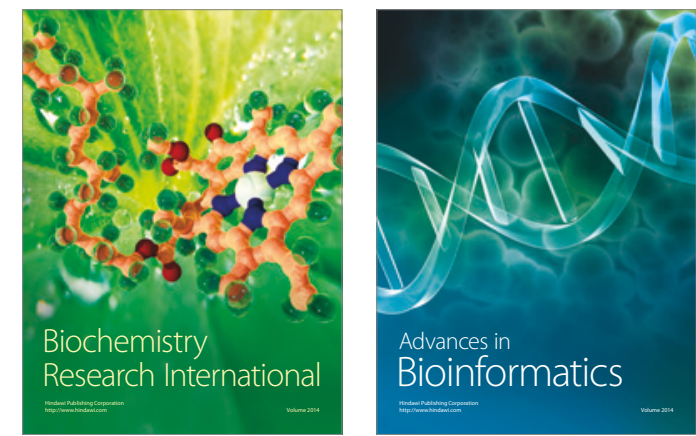

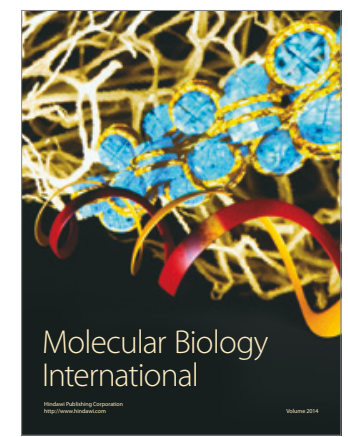

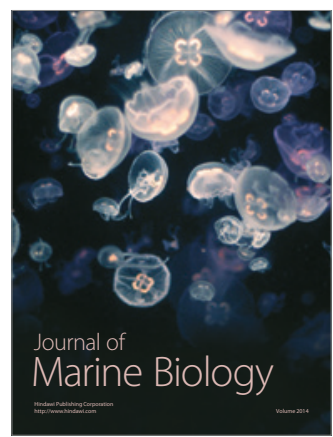

